\title{
First Initial community-acquired meningitis due to extended-spectrum beta-lactamase producing Escherichia coli complicated with multiple aortic mycotic aneurysms
}

\author{
Pierre Weyrich ${ }^{1}$, Nicolas Ettahar ${ }^{1}$, Laurence Legout ${ }^{1 *}$, Agnes Meybeck $^{2}$, Olivier Leroy ${ }^{2}$ and Eric Senneville
}

\begin{abstract}
We report the first case of extended-spectrum beta-lactamase producing $E$. coli community-acquired meningitis complicated with multiple aortic mycotic aneurysms. Because of the acute aneurysm expansion with possible impending rupture on 2 abdominal CT scan, the patient underwent prompt vascular surgery and broad spectrum antibiotic therapy but he died of a hemorrhagic shock. Extended-spectrum beta-lactamase producing E. coli was identified from both blood and cerebrospinal fluid culture before vascular treatment. The present case report does not however change the guidelines of Gram negative bacteria meningitis in adults.
\end{abstract}

Keywords: aortic mycotic aneurysm, ESBL producing Escherichia coli, meningitis

\section{Introduction}

Adult community-acquired meningitis due to $E$. coli is a rare entity. It generally occurs in patients with compromised immune status or cirrhosis. When direct examination of the cerebrospinal fluid (CSF) shows the presence of Gram negative bacilli (GNB), current guidelines recommend the use of a $3^{\text {rd }}$ generation cephalosporin (cefotaxime or ceftriaxone) $[1,2]$. We herein report the first case of extended-spectrum beta-lactamase (ESBL) producing E. coli community-acquired meningitis complicated with multiple aortic mycotic aneurysms.

\section{Observation}

In September 2010, a 59-year-old patient with a history of chronic alcohol and tobacco consumption was admitted to the emergency unit for consciousness disorders and fever. Two days before his admission, the patient had presented headache and nausea.

At admission (09/28), physical examination revealed a frank meningeal irritation, consciousness disorders with a Glasgow Coma Scale (GCS) of 12. The patient's hemodynamic status was stable and, no other physical abnormality

\footnotetext{
* Correspondence: laurence.legout@free.fr

${ }^{1}$ Infectious diseases department, Dron hospital, Tourcoing, France Full list of author information is available at the end of the article
}

was found. WBC count was $3.85 \mathrm{G} / \mathrm{L}$; hemoglobin rate, $14.6 \mathrm{~g} / \mathrm{dl}$; platelets count, $64 \mathrm{G} / \mathrm{L}$; C-reactive protein rate (CRP), $292 \mathrm{mg} / \mathrm{L}$; procalcitonin rate, $21.9 \mathrm{ng} / \mathrm{ml}$ and prothrombine rate, $44 \%$. The renal and hepatic functions were normal. CSF examination showed 440 cells $/ \mathrm{mm} 3$, (neutrophils 62\%, lymphocytes $29 \%$ ) with a glucose and protein rate at $0.01 \mathrm{mmol} / \mathrm{l}$ and $10.35 \mathrm{~g} / \mathrm{l}$, respectively. The chest X-ray, electrocardiogram and cerebral computer tomography $(\mathrm{CT})$ scan were normal. The patient was transferred to the intensive care unit few hours after his admission because of a rapid deterioration of consciousness (GCS 6) and the occurrence of septic shock. Mechanical ventilation, volume resuscitation, hydrocortisone hemisuccinate, vasopressors, platelets transfusion and intravenous empirical broad spectrum antibiotic therapy were administered. The patient received cefotaxime $18 \mathrm{~g} /$ $24 \mathrm{~h}$, amoxicillin $12 \mathrm{~g} / 24 \mathrm{~h}$ and gentamicin $460 \mathrm{mg} / 24 \mathrm{~h}$. Both CSF and blood culture yielded an ESBL producing E. coli resistant to cefalotin (MIC $\geq 64$ ), cefotaxime (MIC $\geq 64$ ), ceftriaxone (MIC $\geq 64$ ), cefixime (MIC2), intermediate to cefepim (MIC 2) and ceftazidime (MIC 2), and susceptible to cefoxitin $(\mathrm{MIC} \leq 4)$, ertapenem $(\mathrm{MIC} \leq 0.5)$, meropenem $(\mathrm{MIC} \leq 0.5)$, imipenem $(\mathrm{MIC} \leq 1)$, gentamicin $(\mathrm{MIC} \leq 1)$, ofloxacin ( $\mathrm{MIC} \leq 0.12$ ) and ciprofloxacin (MIC $\leq 0.25)$. Cefotaxime was switched to meropenem $(6 \mathrm{~g}$ per 
day) combined with ciprofloxacin (1.2 g per day). No abscess was found on brain MRI and thoraco-abdominal CT scan. Meropenem-ciprofloxacin therapy was discontinued after 21 days of treatment (10/18). The patient's condition improved slowly, allowing his extubation after 20 days of mechanical ventilation (10/18). Abnormal CRP rate $(>120 \mathrm{mg} / \mathrm{l})$ persisted at this moment. One week after extubation $(10 / 25)$, the patient was transferred to the department of infectious diseases. At the admission, physical exam showed confusion with slow ideation. There was no abnormality on cardiac, pulmonary and urological examination except a moderate abdominal painful at palpation. Ten days after stopping the antimicrobial treatment (10/28), the laboratory tests showed a persisting elevated rate of CRP $(212 \mathrm{mg} / \mathrm{L})$ and a elevated white blood cell count to $23.6 \mathrm{G} / \mathrm{L}$. Thoracic and abdomi-nopelvic $\mathrm{CT}$ scan were performed which showed multiple mycotic aneurysms of the infra-renal aorta, the aorto-iliac bifurcation and the primitive iliac artery, an inferior vena cava thrombosis, a complete right kidney infarct and a delay in left kidney perfusion. (Figure 1 and 2). The transthoracic echocardiography showed no sign of infectious endocarditis. The patient was transfered to the operating room for aorto-iliac by-pass. No bacteria growth on new bacterial samples but there was taken after antibiotic treatment was started. Unfortunately, the patient died during the surgery of a hemorrhagic shock.

\section{Discussion}

Community-acquired meningitis in adults due to $E$. coli is a rare entity. The main risk factors are alcoholism, cirrhosis, neoplasic diseases, diabetes mellitus, and treatment with immunosuppressive agents [3-7]. Others cases occur frequently in neurosurgery and are usually associated with multi-drug resistant strains [8-11]. In our observation, the patient had no risk factors except a chronic alcoholism and perhaps his dog as animal pet.

In Europe, there is an increasing in $3^{\text {rd }}$ generation cephalosporin resistant E. coli isolates in both hospital setting and the community. CTX-M ESBL is the most common genetic support of resistance in these strains [12]. In our case report, we suspected this mechanism. The spread of E. coli producing ESBL is now well- identified [13].

Blood stream infections due to $E$. coli in adults are often related to underlying urinary or bilary tract or other intra-abdominal infections. Vascular infections and meningitis due to $E$. coli are exceedingly rare and few cases isolated have been reported [14-16]. Diabetes mellitus, previous fluoroquinolone use, recurrent urinary

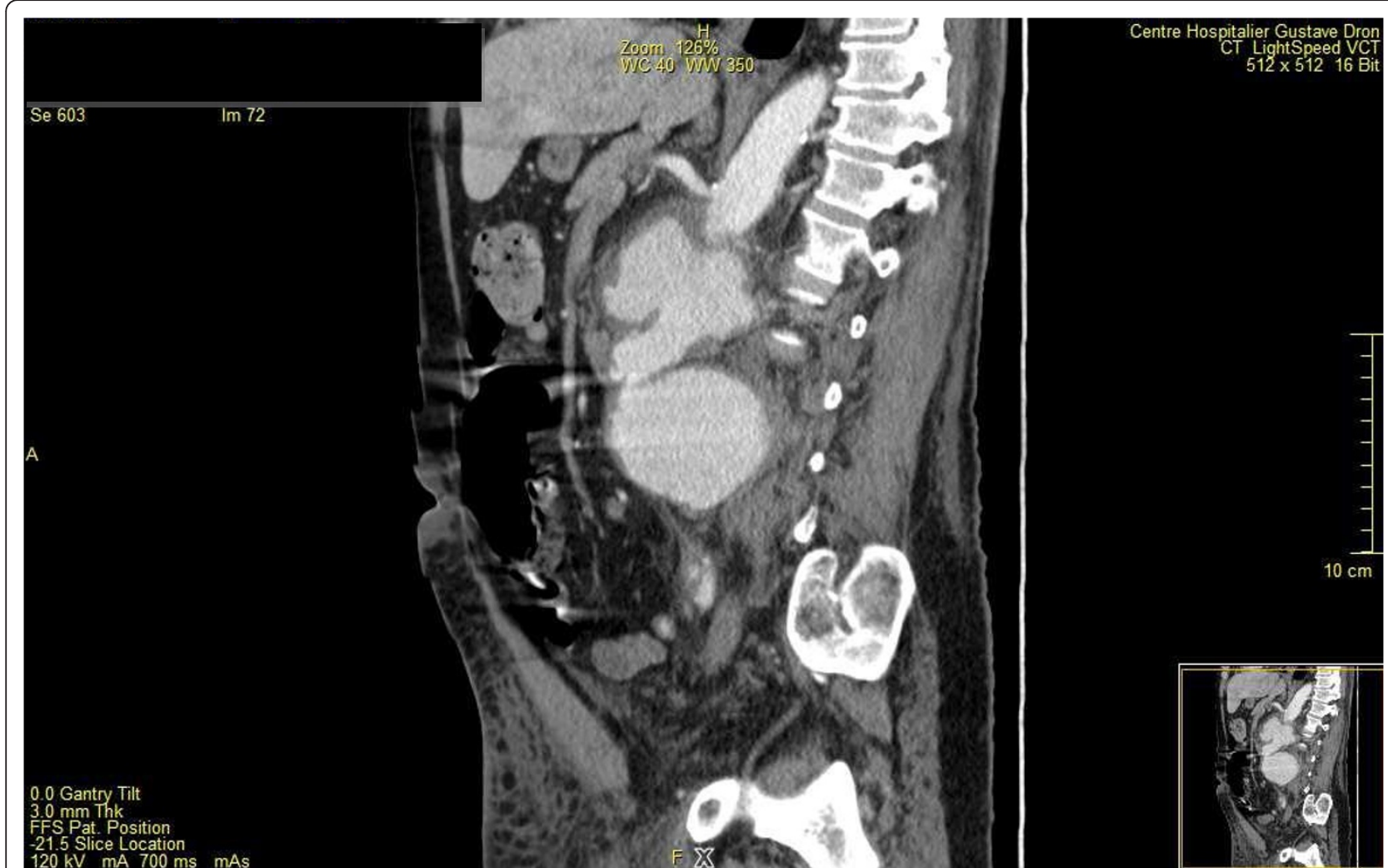

Figure 1 multiple mycotic aneurysms of the infra-renal aorta. 


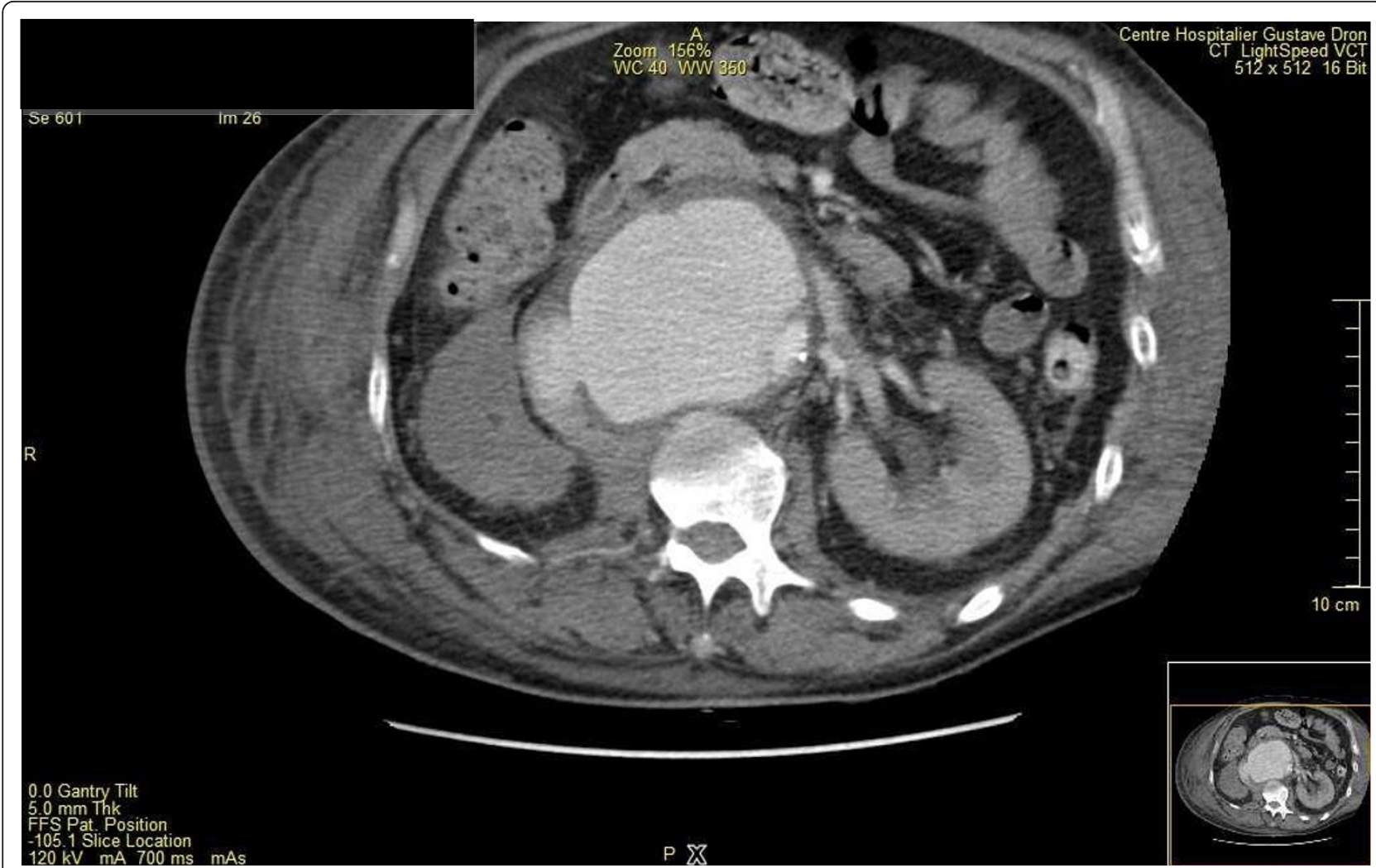

Figure 2 multiple mycotic aneurysms of the infra-renal aorta and inferior vena cava thrombosis, incomplete right kidney infarct and a delay in left kidney perfusion.

tract infection, previous hospital admission and older age in male patients have been identified as risk factors for infection of ESBL-producing E. coli [17]. Recently, Ewers and al. suggested the possibility of inter-species transmission of multiresistant strains of E. coli from human to animal and vice versa [18].

The current guidelines for the management of gram negative bacilli (GNB) related meningitis are well codified and recommend the use of a $3^{\text {rd }}$ generation cephalosporins \pm gentamicin. Alternative therapies are Cefepime, meropenem, aztreonam, fluoroquinolone, and trimethoprim-sulfamethoxazole $[1,2]$. In our case report, meropenem (in association with ciprofloxacin) was used because of the lower risk of seizures compared to imipenem $[19,20]$. Mortality associated with GNB related meningitis varied from 25 to $100 \%$ [7,21]. Lu et al. identified several risk factors for mortality associated to GNB related meningitis: inappropriate initial treatment, septic shock, initial level of consciousness, hyperosmolar hyperglycemic coma, disseminated intravascular coagulation, high CSF lactate levels and leucocytosis. In the multiple logistic regression analysis, only appropriate antimicrobial therapy and septic shock were strongly associated with mortality even after adjusting for other potentially confounding factors [21]. Inappropriate treatment and septic shock were initially present in our patient. The presence of a concomitant aortic mycotic aneurysm was an additional factor of mortality.

Only two cases of mycotic aneurysm in patient presenting initially bacterial meningitis have been reported $[22,23]$. The first case is a 65 -year old woman with ruptured mycotic aneurysm in a patient with pneumococcal meningitis, who died on week later. The second case is a 57 year-old man with a history of CFS fistula and multiple neurosurgical treatment, who developed meningitis complicated with endocarditis and thoracic aortic infection. No bacteria were identified in this second case. The patient was successfully treated with endovascular prosthesis. In the present case report, multiple mycotic aneurysms were suspected because of the sustained bacteremia, the atypical and multiple foci of vascular infection, the normality of the first abdominal CT scan and the rapid evolution of aneurysm. the aortic involvement may be the result of infection of the aortic wall.

\section{Conclusion}

The present case report highlights the risk of meningitis due to ESBL producing E. coli in a patient with apparently no risk factor for this infection with this type of resistant bacilli. This unique observation does not 
provide, however to modify the current guidelines for the treatment of community acquired meningitis in adults.

\section{Consent}

Written informed consent was obtained from the patient's family for publication of this case report and accompanying images.

\section{Acknowledgements}

Thanks to I Bram for her English assistance.

\section{Author details}

'Infectious diseases department, Dron hospital, Tourcoing, France. ${ }^{2}$ Intensive care unit, Dron Hospital Tourcoing, France.

\section{Authors' contributions}

PW, LL, OL, ES participated in the design of the study. LL conceived the case report and participated in its design and coordination. NE and AM collected the data. All authors read and approved the final manuscript.

\section{Competing interests}

LL received speaking honoraria from Novartis.ES received speaking honoraria from Pfizer and Novartis. OL received speaking honoraria from Pfizer and

Novartis. PW, NE and AM had no conflict of interest.

Received: 15 September 2011 Accepted: 9 February 2012

Published: 9 February 2012

\section{References}

1. Practice guidelines for acute bacterial meningitidis (except newborn and nosocomial meningitis). Med Mal Infect 2009, 39(6):356-67.

2. Tunkel AR, Hartman BJ, Kaplan SL, et al: Practice guidelines for the management of bacterial meningitis. Clin Infect Dis 2004, 39(9):1267-84.

3. Bouadma L, Schortgen F, Thomas R, et al: Adults with spontaneous aerobic Gram-negative bacillary meningitis admitted to the intensive care unit. Clin Microbiol Infect 2006, 12(3):287-90.

4. Dorta-Contreras AJ: [Bacterial meningitis due to gram-negative bacilli in immunosuppressed adults who have not undergone neurosurgery]. Rev Neurol 2011, 52(4):255, author reply -6.

5. Laguna-del Estal P, Garcia-Montero P, Agud-Fernandez M, Lopez-Cano Gomez M, Castaneda-Pastor A, Garcia-Zubiri C: [Bacterial meningitis due to gram-negative bacilli in adults]. Rev Neurol 2010, 50(8):458-62.

6. Taziarova M, Holeckova K, Lesnakova A, et al: Gram-negative bacillary community acquired meningitis is not a rare entity in last two decades. Neuro Endocrinol Lett 2007, 28(Suppl 3):18-9.

7. Durand $\mathrm{ML}$, Calderwood SB, Weber DJ, et al: Acute bacterial meningitis in adults. A review of 493 episodes. N Engl J Med 1993, 328(1):21-8.

8. Haile-Mariam T, Laws E, Tuazon CU: Gram-negative meningitis associated with transsphenoidal surgery: case reports and review. Clin Infect Dis 1994, 18(4):553-6.

9. Lu CH, Chang WN, Chuang YC, Chang HW: Gram-negative bacillary meningitis in adult post-neurosurgical patients. Surg Neurol 1999, 52(5):438-43, discussion 43-4.

10. Chen SF, Chang WN, Lu CH, et al: Adult Acinetobacter meningitis and its comparison with non-Acinetobacter gram-negative bacterial meningitis. Acta Neurol Taiwan 2005, 14(3):131-7.

11. O'Neill E, Humphreys H, Phillips J, Smyth EG: Third-generation cephalosporin resistance among Gram-negative bacilli causing meningitis in neurosurgical patients: significant challenges in ensuring effective antibiotic therapy. J Antimicrob Chemother 2006, 57(2):356-9.

12. Courpon-Claudinon A, Lefort A, Panhard X, et al: Bacteraemia caused by third-generation cephalosporin-resistant Escherichia coli in France: prevalence, molecular epidemiology and clinical features. Clin Microbiol Infect 2011, 17(4):557-65.

13. Meier S, Weber R, Zbinden R, Ruef C, Hasse B: Extended-spectrum betalactamase-producing Gram-negative pathogens in community-acquired urinary tract infections: an increasing challenge for antimicrobial therapy. Infection 2011.

14. Brown SL, Busuttil RW, Baker JD, Machleder HI, Moore WS, Barker WF: Bacteriologic and surgical determinants of survival in patients with mycotic aneurysms. J Vasc Surg 1984, 1(4):541-7.

15. Muller BT, Wegener OR, Grabitz K, Pillny M, Thomas L, Sandmann W: Mycotic aneurysms of the thoracic and abdominal aorta and iliac arteries: experience with anatomic and extra-anatomic repair in 33 cases. J Vasc Surg 2001, 33(1):106-13.

16. McCann JF, Fareed A, Reddy S, Cheesbrough J, Woodford N, Lau S: Multiresistant Escherichia coli and mycotic aneurysm: two case reports. J Med Case Reports 2009, 3:6453.

17. Rodriguez-Bano J, Navarro MD, Romero L, et al: Epidemiology and clinical features of infections caused by extended-spectrum beta-lactamaseproducing Escherichia coli in nonhospitalized patients. J Clin Microbiol 2004, 42(3):1089-94.

18. Ewers C, Grobbel M, Stamm I, et al: Emergence of human pandemic O25: H4-ST131 CTX-M-15 extended-spectrum-beta-lactamase-producing Escherichia coli among companion animals. J Antimicrob Chemother 2010, 65(4):651-60.

19. Klugman KP, Dagan R: Randomized comparison of meropenem with cefotaxime for treatment of bacterial meningitis. Meropenem Meningitis Study Group. Antimicrob Agents Chemother 1995, 39(5):1140-6.

20. Mohr JF: Update on the efficacy and tolerability of meropenem in the treatment of serious bacterial infections. Clin Infect Dis 2008, 47(Suppl 1): S41-51.

21. Lu CH, Chang WN, Chuang YC, Chang HW: The prognostic factors of adult gram-negative bacillary meningitis. J Hosp Infect 1998, 40(1):27-34.

22. Mincheff TV, Cooler AW: Ruptured mycotic aneurysm presenting initially with bacterial meningitis. Am Surg 2008, 74(1):73-5.

23. Lopes R, Almeida J, Dias P, Pinho P, Maciel MJ: Early diagnosis of nonaneurysmal infectious thoracic aortitis using transesophageal echocardiogram in a patient with purulent meningitis. Cardiol Res Pract 2009, 2009:769694.

doi:10.1186/1476-0711-11-4

Cite this article as: Weyrich et al.: First Initial community-acquired meningitis due to extended-spectrum beta-lactamase producing Escherichia coli complicated with multiple aortic mycotic aneurysms. Annals of Clinical Microbiology and Antimicrobials 2012 11:4.

\section{Submit your next manuscript to BioMed Central and take full advantage of:}

- Convenient online submission

- Thorough peer review

- No space constraints or color figure charges

- Immediate publication on acceptance

- Inclusion in PubMed, CAS, Scopus and Google Scholar

- Research which is freely available for redistribution

Submit your manuscript at www.biomedcentral.com/submit
C Biomed Central 